\title{
Late Coil Migration after Embolization of Cerebral Aneurysms - Case Series
}

\section{Migração tardia de coil após embolização de aneurismas cerebrais - série de casos}

\author{
Luana Antunes Maranha Gatto ${ }^{1}$ Luana Bandeira Rocha ${ }^{2}$ Gelson Luis Koppe ${ }^{3}$ Zeferino Demartini Jr ${ }^{1}$ \\ ${ }^{1}$ Department of Neurosurgery and Interventional Neuroradiology, \\ Hospital Universitário Cajuru da Pontifícia Universidade Católica \\ (HUC-PUC), Curitiba, PR, Brazil \\ 2 Department of Neurosurgery, HUC-PUC, Curitiba, PR, Brazil \\ ${ }^{3}$ Department of Interventional Neuroradiology, HUC-PUC, Curitiba,

\begin{abstract}
Address for correspondence Luana Antunes Maranha Gatto, MD, MBA, Departamento de Neurocirurgia e Neurorradiologia Intervencionista, Hospital Universitário Cajuru da Pontifícia Universidade Católica (HUC-PUC), Av. São José, 300, Cristo Rei, Curitiba, PR, Brazil 80050-350 (e-mail: luanamaranha@yahoo.com.br).
\end{abstract} PR, Brazil

Arq Bras Neurocir 2018;37:71-75.

\author{
Abstract \\ Keywords \\ - endovascular \\ procedures \\ - interventional \\ radiography \\ - intracranial aneurysm \\ - postoperative \\ complications \\ - intracranial embolism \\ - embolic protection \\ devices
}

\section{Resumo}

Background Coil migration after cerebral aneurysm embolization is a very rare complication. It can take place early or late in the postoperative period, evolving asymptomatic and causing severe neurological deficits. Ruptured aneurysms of anterior communicant artery were the most frequent reported examples in the literature.

Case Report We report three cases of patients with unruptured aneurysms treated with coils and remodeling balloon technique. The first case was that of a left posterior communicating artery aneurysm with coil migration to a distal cortical branch of ipsilateral middle cerebral artery (MCA). The patient had mild paresthesia in the arm for a few days. The second one was a fenestrated basilar artery aneurysm with coil migration to the $\mathrm{P} 2$ segment of the left posterior cerebral artery. The patient was fully asymptomatic. The third case was a MCA aneurysm with coil migration to the M3 segment. There were no ischemic complications, and all patients underwent a new endovascular procedure.

Conclusions Coil migration is a rare but not always severe complication. Antiplatelet agents are recommended even if the coil migration is asymptomatic.

Introdução A migração de coil após embolização de aneurisma cerebral é uma complicação muito rara. Ela pode ocorrer no período pós-operatório tanto precoce quanto tardio, evoluindo assintomático ou causando graves déficits neurológicos. Aneurismas rotos da artéria comunicador anterior foram os exemplos mais frequentes relatados na literatura. received

December 31, 2017

accepted

February 9, 2018

published online

March 26, 2018
DOI https://doi.org/

10.1055/s-0038-1639347.

ISSN 0103-5355.
Copyright $(2018$ by Thieme Revinter

Publicações Ltda, Rio de Janeiro, Brazil
License terms

(c) (i) $\ominus$ (\$) 


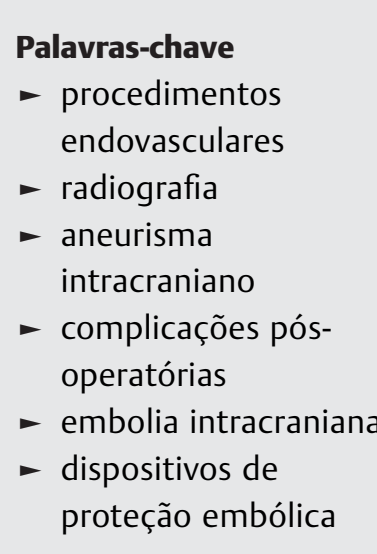

Relato de Caso Relatamos três casos de pacientes com aneurismas não rotos tratados com coils e técnica de remodelagem com balão. O primeiro caso foi de um aneurisma de artéria comunicante posterior com migração do coil para um ramo cortical distal da artéria cerebral média (ACM) ipsilateral. A paciente apresentou parestesia leve no braço por alguns dias. $\mathrm{O}$ segundo foi um aneurisma de artéria basilar fenestrada com migração de coil para o segmento P2 da artéria cerebral posterior esquerda. O paciente ficou totalmente assintomático. O terceiro caso foi de um aneurisma de ACM com migração do coil para o segmento M3. Não houve complicações isquêmicas, e todos os pacientes foram submetidos a novo procedimento endovascular.

Conclusões Migração de coil é uma complicação rara, mas nem sempre grave. Antiagregantes plaquetários são recomendados mesmo se a migração do coil for assintomática.

\section{Introduction}

Embolization with platinum Guglielmi detachable coils (GDCs) is a technique introduced in 1990 to avoid expansion and rupture of cerebral aneurysms. ${ }^{1}$ The goal of the treatment of cerebral aneurysms is to prevent rupture and vasospasm, reducing mortality associated with bleeding. ${ }^{2}$ Posteriorly, other adjunctive devices have been produced to increase safety and efficacy, especially in the case of aneurysms with wide necks: stents and balloons. An aneurysm is considered to have a wide-neck when the neck is $\geq 4 \mathrm{~mm}$, or when the dome/ neck ratio is $<1.5-2 .{ }^{3}$ With the emergence of techniques and devices facilitating the cerebral aneurysm embolization, the number of aneurysms considered embolizable increased, as did the number of complications.

Complications happen in $8.6-18.6 \%$ of cases with a median of $\sim 10.6 \%$, and include thromboembolic events (2.5$14.5 \%)$, perforation of aneurysm $(2.3-4.7 \%)$, parent artery obstruction (2-3\%); collapsed GDCs ( $8 \%$ ), GDC malposition (14.6\%), and GDC migration (0.5-3\%). ${ }^{2}$

The coil protrusion or migration tends to occur after incomplete wrapping of a wide neck aneurysm. The migrated coils can form thrombi, which may cause distal vessel occlusion. ${ }^{4}$ If the patients with minimal coil protrusion have no ischemic symptoms, they may be treated with persistent systemic anticoagulation. However, in cases of symptomatic protrusion or coils migration, the patients must be recovered through endovascular procedure or surgery to avoid a new ischemic problem. ${ }^{4}$ There is no standard recommended method of coil displaced retrieval. Any evidence of embolic phenomena or thrombus aggregation related to the coil requires intervention. ${ }^{5}$ On identification of the complication, the patient should receive a loading dose of antiplatelet medication. On the other hand, the use of stent retrievers presents a simple, safe, and effective choice for removal of prolapsed coils during aneurysm coiling. ${ }^{5}$

In this case series, we have analyzed three cases of embolization with coil migration after the procedure. During the course of 8 years, we have coiled 324 aneurysms, and 10 others have had migration during the procedure. Now, we report an uncommon occurrence of olygo-asymptomatic presentation of this issue.

\section{Case 1 (-Fig. 1)}

A 54-year-old female patient who was a heavy smoker presented with 6 months of severe headache and normal neurological examination. The brain computed tomography (CT) showed a large lesion suggestive of aneurysm, and the digital subtraction angiography (DSA) confirmed a left posterior communicating artery (PComA) aneurysm, with $9 \mathrm{~mm}$ in greatest diameter, neck with $2 \mathrm{~mm}$ and $4 \mathrm{~mm}$ of domus. After being offered an explanation of the risks and benefits and of the differences between clipping and embolization, the patient opted for the endovascular procedure.

An unmarkable balloon-assisted embolization with GDCs was performed with satisfactory postoperative DSA ( - Fig. 1C). We used the following eV3 Axium coils: 3D $4 \times 8$, Helix $3 \times 8$, Helix $2 \times 4$ and Helix $2 \times 2$. A routine CT on the first postoperative day showed metallic artifact corresponding to two GDC casts. The control DSA showed a protruded coil from the aneurysm with residual neck and another migrated GDC in a branch of the MCA M4 segment. Acetylsalicylic acid (ASA) was started, and the patient was discharged asymptomatic 3 days later.

She returned referring mild and sporadic paraesthesia in the distal right arm, which stopped 20 days later. The magnetic resonance imaging (MRI) did not show any changes. She opted again for the endovascular procedure, which was performed again with balloon remodeling and GDC 45 days later. The final angiographic control was satisfactory. She was discharged on the second postoperative day, ASA was kept for 6 months and the outcome was satisfactory (zero in the modified Rankin Scale [mRS] in 4 years).

\section{Case 2 (-Fig. 2)}

A 59-year-old female patient presenting with saccular aneurysm in a fenestrated basilar artery diagnosed during a migraine investigation, with $4 \mathrm{~mm}$ in greatest diameter, 


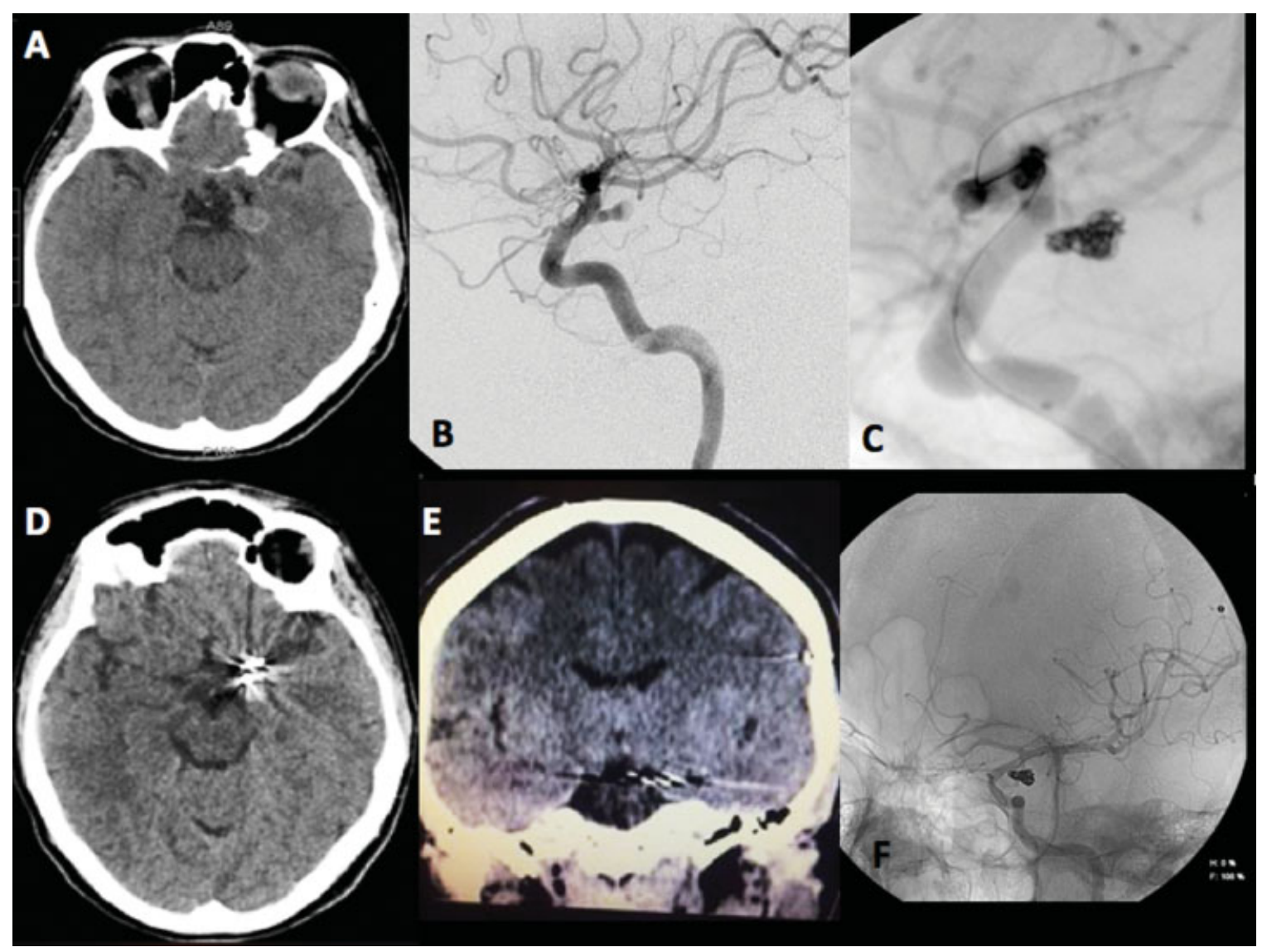

Fig. 1 Case 1 - 54-year-old female patient.

neck with $2 \mathrm{~mm}$ and domus with $4 \mathrm{~mm}$. She was a heavy smoker and had hypertension and depression, without neurological deficits.

A remodeling balloon-assisted embolization was performed with GDC achieving satisfactory aneurysm occlusion. We used the following eV3 Axium coils: $3 \mathrm{D} 3 \times 8$, Helix $3 \times 8$, Helix $3 \times 4$ and Helix $2 \times 6$. A control CT on the first postoperative day showed metallic artifact corresponding to the cast of GDCs in the aneurysm in addition to another in the left crural cistern. The control DSA showed displacement of the cast of coils and a migrated coil in the left posterior cerebral artery (PCA) (P2 segment). The MRI study ruled out ischemia. There were no symptoms, and the patient was discharged 3 days later, using acetylsalicylic acid (ASA). Another endovascular procedure was performed 56 days after the first one, with stent and GDCs, with good angiographic results. The patient was discharged on the second postoperative day and had good outcome at follow-up, using ASA and Clopidogrel (mRS zero in 2.5 years).

\section{Case 3 (-Fig. 3)}

A 71-year-old man with systemic high blood pressure, diabetes, post-coronary angioplasty and left lacunar stroke. Normal neurological examination. Two years earlier, he had a subarachnoid hemorrhage due to rupture of a right ophthalmic aneurysm, which was clipped. He still had a second small saccular aneurysm in the left MCA bifurcation, with $3 \mathrm{~mm}$ of domus and neck with $2 \mathrm{~mm}$ besides a family history of ruptured brain aneurysms (mother and uncle).

We proceeded to a remodeling balloon-assisted embolization with GDCs without intercurrences. We used the following eV3 Axium coils: 3D $2 \times 2$ and Helix $1.5 \times 2$. At the end, the angiographic control was satisfactory. A routine $\mathrm{CT}$ on the first postoperative daydid not show any complication and he was discharged. A DSA performed 6 months after the surgery showed displacement of the cast of coils and a migrated coil in the M3 segment. The patient was asymptomatic throughout this follow-up period.

Another endovascular procedure was performed 214 days after the first one, made again with balloon remodeling and GDCs. The final angiographic control was satisfactory. The patient was discharged on the second postoperative day and had good outcome at follow-up (mRS zero in 1.5 years).

\section{Discussion}

Coil migration is a rare condition; it represented only $0.5 \%$ of the complications in a study with 403 patients treated for ruptured cerebral aneurysms, ${ }^{1}$ while most of the reported cases are symptomatic and may cause great morbidity by the arterial occlusion and consequent ischemic symptoms. 


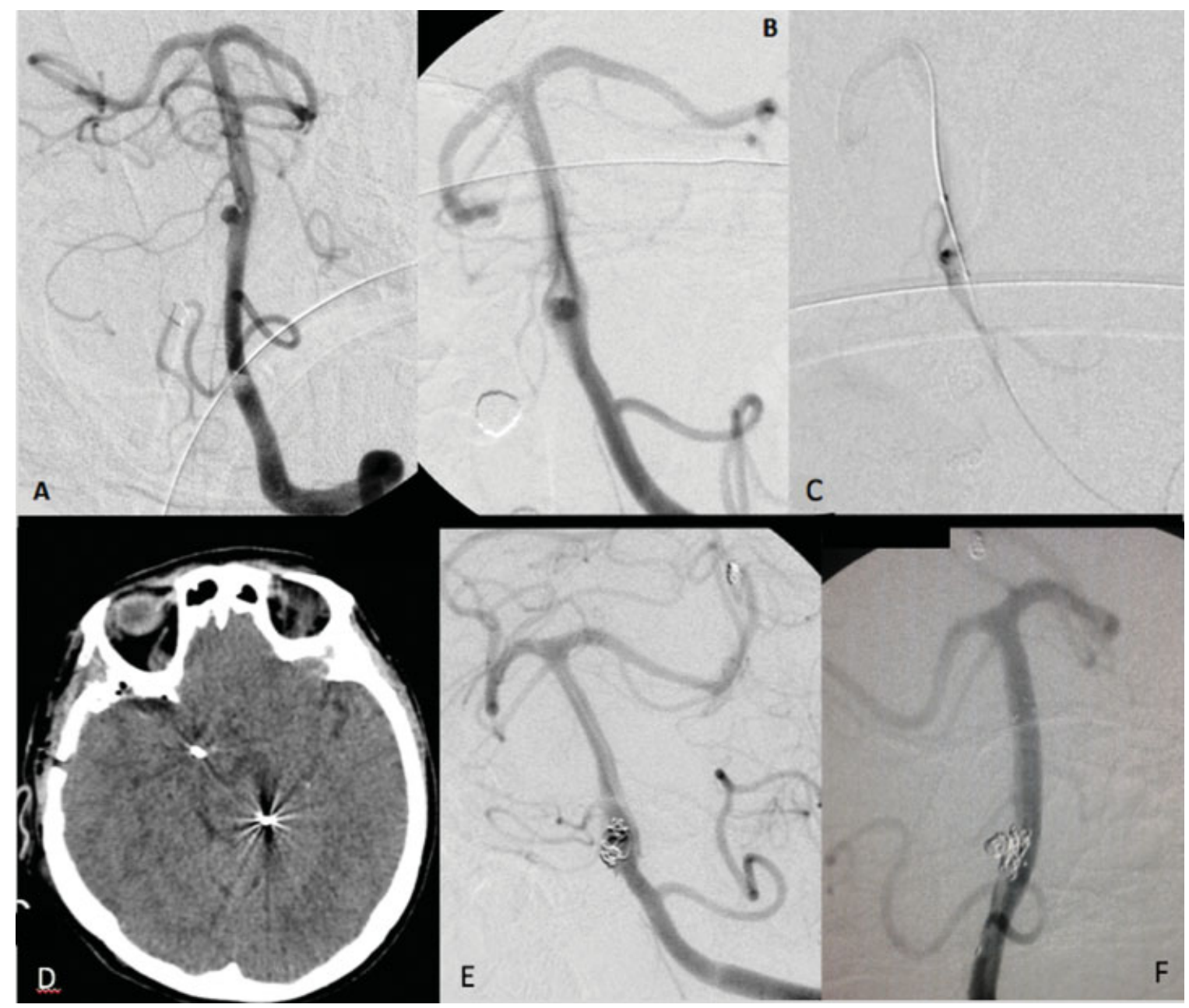

Fig. 2 Case 2 - 59-year-old female patient.

Severe neurological consequences have been described in other reports. ${ }^{4,6,7}$ One case demonstrated that coil migration represents a rare but potentially severe complication of cerebral aneurysm embolization. A man with subarachnoid hemorrhage had a delayed ( 8 days after the procedure) migration of a coil loop after adjunctive balloon remodeling of an anterior communicating artery (AComA) aneurysm causing ischemia on the anterior cerebral artery and paresia of the lower extremity. ${ }^{7}$

In another case, although delayed (30 days after the procedure) the coil migrated to the pericallosal artery from a ruptured AComA aneurysm. The patient was asymptomatic and there was no evidence of ischemia in the CT scan. The authors believe that the aneurysm was larger than previously imagined and that the use of balloon remodeling could impede the migration. The patient opted for surgical treatment. ${ }^{6}$

A retrospective study with 346 cases of cerebral aneurysms embolized from 1997 to 2001 had 5 complications related to GDCs. Two patients with AComA and middle cerebral artery (MCA) aneurysms had GDCs migration to segments A2 and M2, respectively. They started with ischemic symptoms after 48 hours. Both underwent craniotomy and removal of GDCs, once the migration went in the direc- tion of the main artery. There was reversal of symptoms, because the main source of ischemic symptoms is the formation of small emboli around the migrated spirals. ${ }^{4}$

Ding et $\mathrm{al}^{8}$ identified 16 publications with 37 reported cases of migrated coil retrieval consisting of 10 case reports and 6 case series. Most of the aneurysms presented with rupture (65\%) and were located in the anterior circulation (70\%), but the migration occurred and was seen during the procedure. They proceeded to endovascular retrieval with microwires, alligator retrieval device, MERCI devices, snares and stentrievers, and just one case needed microsurgical extraction following failed endovascular removal. ${ }^{8}$

We indicated only antiaggregation because the coil migration went to a very distal branch of the MCA in the first case, and because all patients were asymptomatic. An antiplatelet regimen should be used until endothelialization of the coil, but the aneurysm treatment must be completed if there is a residual neck. ${ }^{4}$ Our standard antiplatelet regimen comprises $100 \mathrm{mg}$ of ASA and $75 \mathrm{mg}$ of Clopidogrel daily, only for wide neck aneurysms that will receive a stent. They are started at least 10 days before the elective procedure. As we do not have tests to see if the antiplatelet drugs are working, they are continued for at least 6 months. 


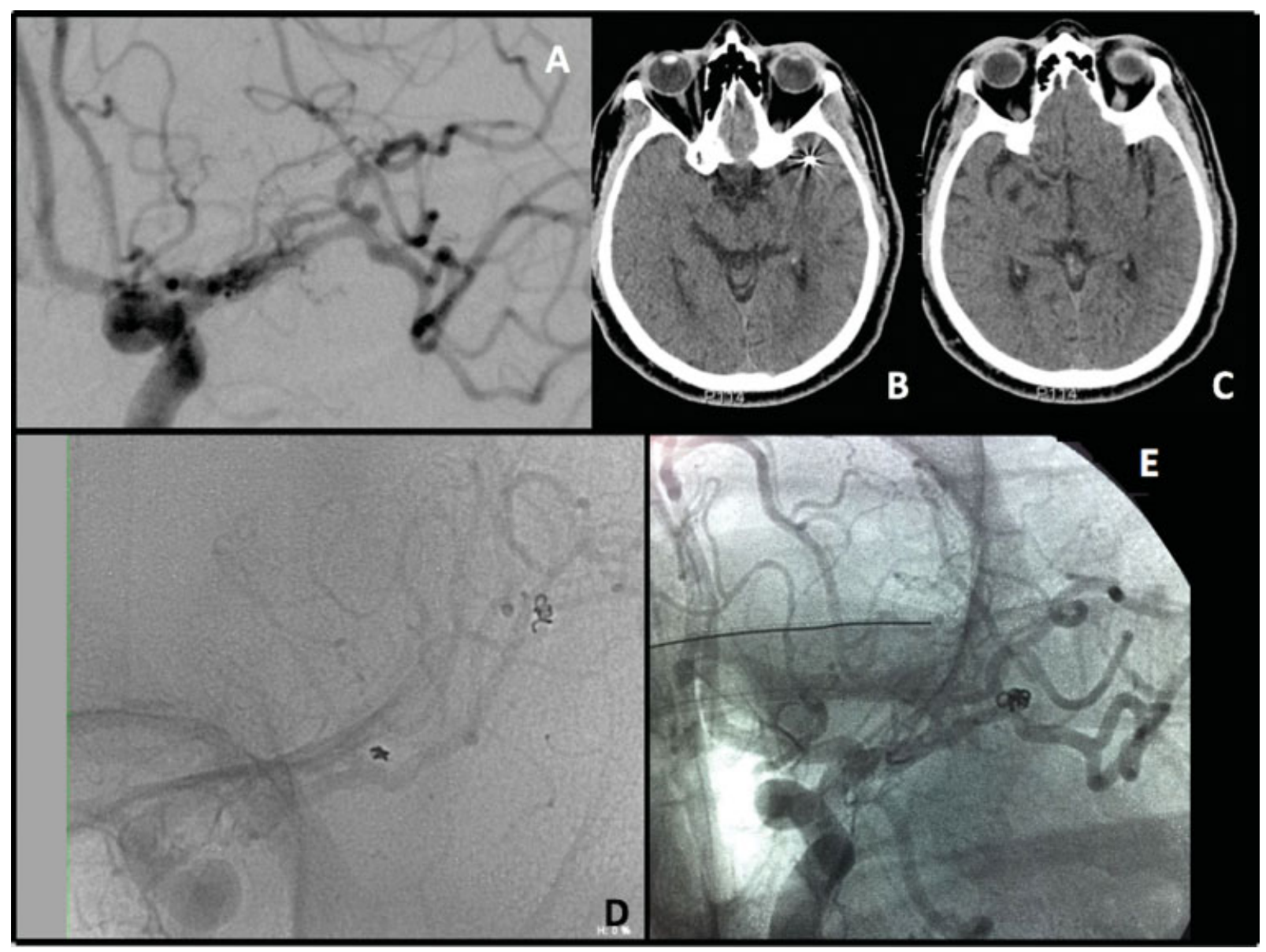

Fig. 3 Case 3 - 71-year-old man.

In our reported cases, it is important to note that the dome-neck relation was proper, making the coil embolization a good option. Besides, a balloon was used during the procedure, since it is a complication prevention tool. ${ }^{3}$ In all cases, the coils remained stable just as described in most coil migration cases. ${ }^{6}$ This event confirms that stable coils may change position and migrate, as it happened in a reported case that describes the emergence of late symptoms despite a successful embolization performed 8 days before. $^{7}$

The time between the initial procedure and detection of the migration varies from days to months. In one of the cases, the detection happened only 5 months later, at the control arteriography. ${ }^{4}$ However, no control CT was performed in the first day after embolization, as it is recommended at our clinic.

\section{Conclusion}

These cases illustrate an unusual complication of cerebral aneurysm embolization. The literature review showed that the majority of cases of ruptured aneurysms take place in the AComA. Coil migration is a rare but not always severe complication.

\section{References}

1 Viñuela F, Duckwiler G, Mawad M. Guglielmi detachable coil embolization of acute intracranial aneurysm: perioperative anatomical and clinical outcome in 403 patients. 1997. J Neurosurg 2008;108(04):832-839

2 Ontario HQ; Health Quality Ontario. Coil embolization for intracranial aneurysms: an evidence-based analysis. Ont Health Technol Assess Ser 2006;6(01):1-114

3 Piotin M, Blanc R. Balloons and stents in the endovascular treatment of cerebral aneurysms: vascular anatomy remodeled Review Article. Front Neurol 2014;5:41

4 Kojima T, Miyachi S, Negoro M, et al. Coil retrieval following embolization of cerebral aneurysms. Interv Neuroradiol 2003;9 (Suppl 1):149-155

5 Leslie-Mazwi TM, Heddier M, Nordmeyer H, et al. Stent retriever use for retrieval of displaced microcoils: a consecutive case series. AJNR Am J Neuroradiol 2013;34(10):1996-1999. Doi: 10.3174/ ajnr.A3552

6 Banerjee AD, Guimaraens L, Cuellar H. Asymptomatic delayed coil migration from an intracranial aneurysm: a case report. Case Rep Vasc Med 2011;2011:901925

7 Fiorella D, Kelly ME, Moskowitz S, Masaryk TJ. Delayed symptomatic coil migration after initially successful balloon-assisted aneurysm coiling: technical case report. Neurosurgery 2009;64 (02):E391-E392, discussion E392

8 Ding D, Liu KC. Management strategies for intraprocedural coil migration during endovascular treatment of intracranial aneurysms. J Neurointerv Surg 2014;6(06):428-431 